\title{
Erratum to: Moving in groups: how density and unpredictable motion affect predation risk
}

\author{
Nicholas E. Scott-Samuel ${ }^{1}$ - Gavin Holmes ${ }^{2}$. \\ Roland Baddeley ${ }^{1}$ - Innes C. Cuthill ${ }^{3}$
}

Published online: 18 April 2015

(C) Springer-Verlag Berlin Heidelberg 2015

Erratum to: Behavioral Ecology and Sociobiology

DOI 10.1007/s00265-015-1885-1

The authors of the above article wanted to change the Data accessibility statement to: Data are deposited on Dryad (www.datadryad.org). DOI http://dx.doi.org/10.5061/dryad. $3 \mathrm{f8} 63$.

The online version of the original article can be found at http://dx.doi.org/ 10.1007/s00265-015-1885-1.

$\square$ Nicholas E. Scott-Samuel

n.e.scott-samuel@bris.ac.uk

1 School of Experimental Psychology, University of Bristol, Bristol, UK

2 School of Psychology, Cardiff University, Cardiff, UK

3 School of Biological Sciences, University of Bristol, Bristol, UK 